DOI: $10.14451 / 2.129 .45$

\title{
ТЕНДЕНЦИИ РАЗВИТИЯ МАЛОГО И СРЕДНЕГО ПРЕДПРИНИМАТЕЛЬСТВА В ЧЕЧЕНСКОЙ РЕСПУБЛИКЕ
}

\author{
(c) 2019 Магомадов Эмин Мухадинович \\ Чеченский государственный университет, Чеченская Респ., Грозный \\ E-mail: chgu@yandex.ru
}

В статье проводится анализ развития малого и среднего предпринимательства в Чеченской Республике, предлагаются меры, которые способны решить возникающие проблемы.

Развитие малого и среднего предпринимательства в Чеченской Республике должно стать одним из наиболее ярких проявлений взаимных интересов и взаимозависимости регионов Юга России. Это должно привести к увеличению объемов разнообразных хозяйственных связей и контактов между регионами.

Серьезные импульсы, стимулирующие углубление этих связей, создаются в результате становления процесса современной экономической интеграции. Стремление Чеченской Республики использовать межрегиональную кооперацию для решения неотложных проблем своего социально-экономического развития стимулирует осуществление межрегионального хозяйственного сотрудничества.

По состоянию на 1 января 2014 г. в Российской Федерации зарегистрировано 5,6 млн. субъектов малого и среднего предпринимательства, на которых занято $25 \%$ от общей численности занятых в экономике.

В целом, если рассматривать демографию организаций, то в Чеченской Республике в настоящее время коэффициенты рождаемости совпадают со средне российскими значениями, а в 2009 году превышали рождаемость предприятий по России более чем в два раза.

Показатели официальной ликвидации организаций также сравнимы со средне российскими значениями, и только в 2016 году наблюдается разнонаправленная динамика. Как в Чеченской Республике, так и в целом по России демография организаций характеризуется увеличением относительного количества ликвидаций и отсутствием роста рождаемости организаций в последние годы (см. рис. 1).

С 2005 по 2012 годы в Чеченской Республике рождаемость организаций превышала смертность. Исключением можно считать 2012-2014 годы, когда прирост количества организаций был отрицательным. В 2015-2016 гг. число официально ликвидированных организаций не превышает количество зарегистрированных. Однако общие тенденции говорят о росте ко-

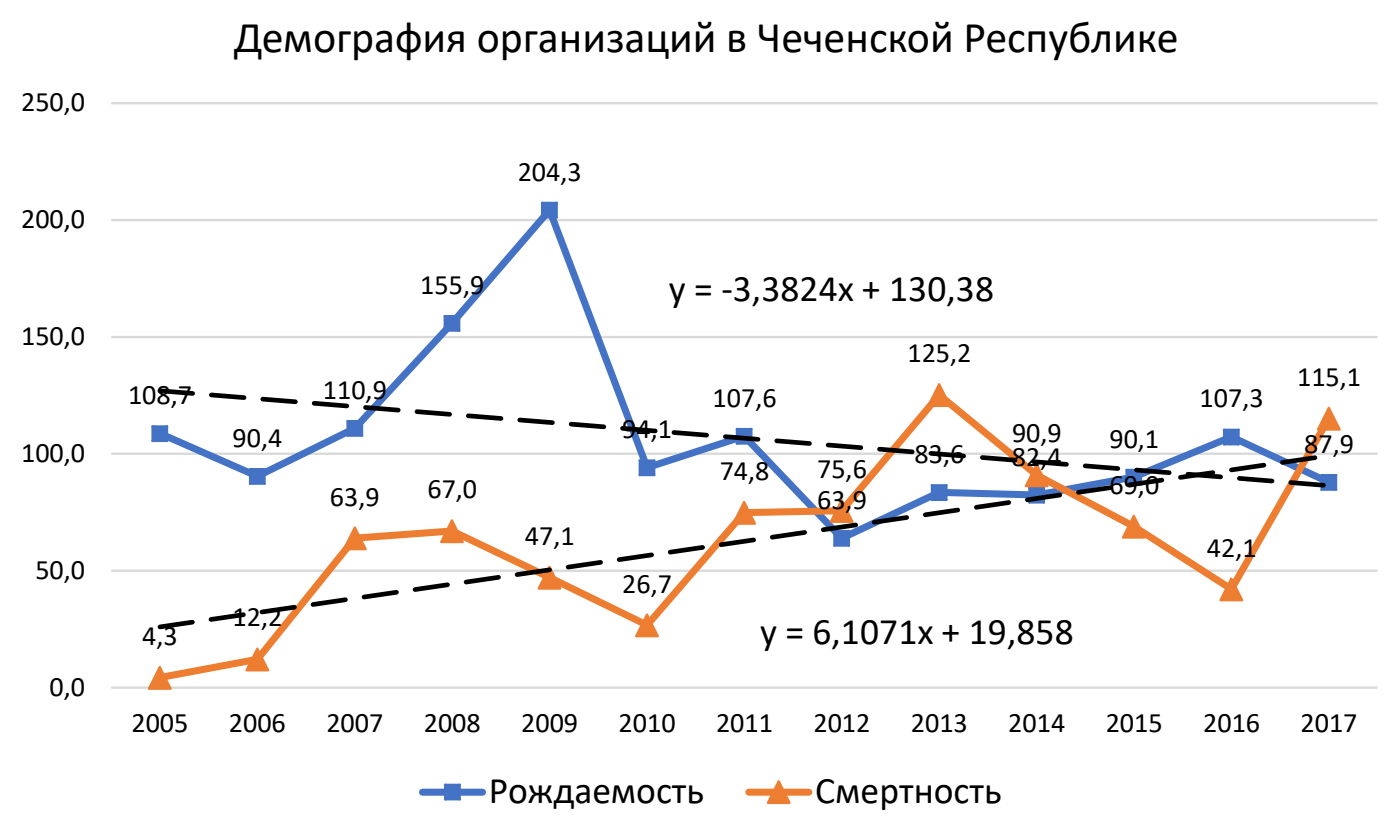

Puc. 1. Динамика «естественного движения» организаций в Чеченской Республике, промилле 
эффициента официальной ликвидации организаций в Чеченской Республике на фоне снижающейся рождаемости. Уравнение линейного тренда $\mathrm{y}=6.1071 \mathrm{x}+19.858$ говорит о среднем ежегодном увеличении количества ликвидации на 6 организаций в расчете на каждые 1000 существующих организаций. В то же самое время линейный тренд $\mathrm{y}=-3.3824 \mathrm{x}+130.38$ свидетельствует о ежегодном снижении рождаемости в среднем на 3 организации в расчете на 1000 организаций.

В первом полугодии 2018 года тенденция превышения смертности организаций их рождаемости сохранилась во всех федеральных округах. В Северо-Кавказском федеральном округе число ликвидированных предприятий в два раза превышает число вновь зарегистрированных. Если наблюдаемая динамика рожда- емости и смертности организаций сохранится, то можно будет говорить о том, что демография предприятий подобна демографии населения в среднем по России. Известно, что демография организаций - один из показателей состояния бизнес-климата в стране.

Анализ динамики рождаемости и официальной ликвидации организаций в Чеченской Республике говорит о том, что здесь демография населения, кардинально отличающаяся от среднероссийских тенденций в лучшую сторону, не стала существенным фактором воздействия на демографию организаций (см. рис. 2).

В Чеченской Республике количество ликвидированных организаций не намного превысило число вновь зарегистрированных.

Как видно из рисунка 3, в Чеченской Республике в два раза выше «младенческая смерт-

Зарегистрированные и официально ликвидированные организации в I полугодии 2018 года

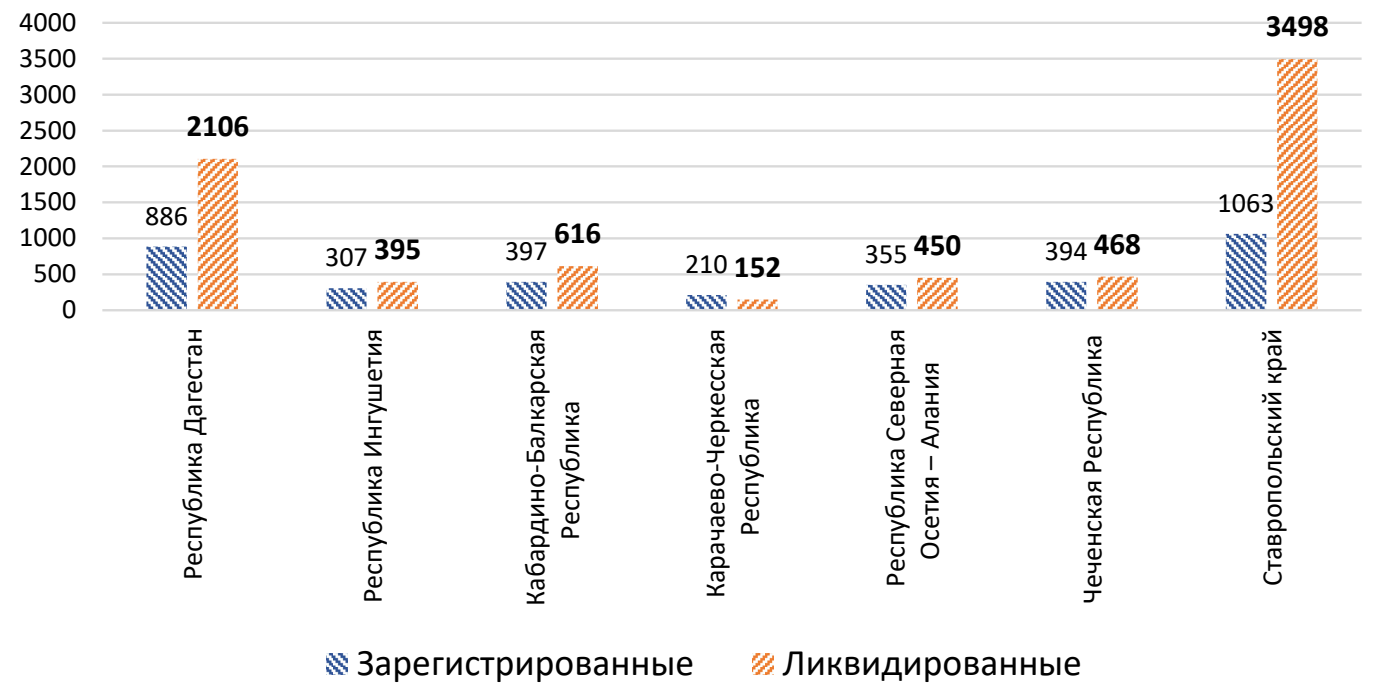

Puc. 2. Соотношение числа зарегистрированных и официально ликвидированных организаций по субъектам СКФО в первом полугодии 2018 года

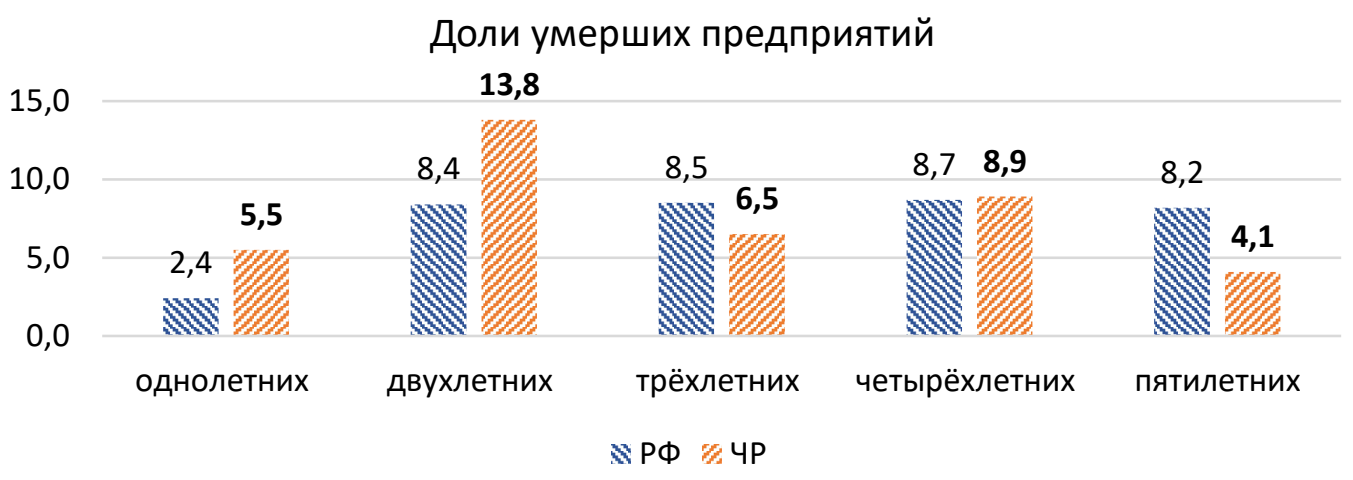

Puc. 3. Возрастная структура умерших предприятий в Чеченской республике в 2017 году 
ность», чем в среднем по России,- 5,5\% ликвидированных однолетних предприятий против $2,4 \%$ в среднем по России. Больше всего в относительном выражении в Чеченской республике ликвидируются двухлетние предприятия - их доля среди всех ликвидированных предприятий в 2017 году близка к $14 \%$.

Анализ динамики численности предприятий малого и среднего предпринимательства (см. табл. 1) за последние годы показывает неустойчивость тенденций - за короткий временной интервал численность микропредприятий, малых и средних предприятий изменялась разнонаправленно, рост их количества мог сменяться их стремительным снижением и наоборот.

Сравнивая тенденции численности средних предприятий в Чеченской Республике со среднероссийскими значениями (см. табл. 2), видим, что относительные изменения совпадали со среднероссийскими тенденциями до 2014 года было заметное снижение их численности в 2011 году, более чем наполовину. До 2014 года колебания численности средних предприятий находились в небольшом диапазоне - около 10\%. В 2015 году в Чеченской Республике произошло многократное увеличение численности средних предприятий. Общая тенденция изменения численности средних предприятий в Чеченской Республике положительная - параметры линейного тренда $\mathrm{y}=22.059 \mathrm{x}+14.286$ говорят об увеличении их численности в среднем на 22\% ежегодно, что выгодно отличает Чеченскую Республику от среднероссийских тенденций. В среднем по России наблюдается тенденция снижения численности средних предприятий - параметры линейного тренда $\mathrm{y}=-4.0981 \mathrm{x}+81.595$ показывают в среднем снижение на $4 \%$ ежегодно. Несмотря на общую положительную тенденцию, следует обратить внимание на то, что после заметного увеличения численности средних предприятий в Чеченской Республике в 2015 году (229\% относительно 2010 года), в 2016 году вновь произошло снижение их количества - до 176\% относительно 2010 года. Совпадение направлений изменения численности средних предприятий в 2015 и 2016 годах в Чеченской Республике и в среднем по России говорит о наличии общих факторов, сильно воздействующих на исследуемую динамику.

Тенденцию численности малых предприятий в Чеченской Республике за последние годы нельзя считать устойчивой (см. табл. 3) - их количество в некоторые годы менялось в несколько раз в сторону увеличения или уменьшения. Например, в 2011 году наблюдалось снижение их численности в три раза по отношению к предшествующему году, а в 2015 произошел рос количества малых предприятий более чем в три раза. Общая тенденция, описываемая линейным трендом $\mathrm{y}=7.749 \mathrm{x}+35.583$ показывает в среднем

Таблица 1. Динамика численности малых и средних предприятий в Чеченской Республике (на конец года)

\begin{tabular}{|l|c|c|c|c|c|c|c|}
\hline & 2010 & 2011 & 2012 & 2013 & 2014 & 2015 & 2016 \\
\hline Средние предприятия & 17 & 7 & 8 & 11 & 10 & 39 & 30 \\
\hline Малые предприятия & 218 & 65 & 62 & 35 & 102 & 385 & 149 \\
\hline Микропредприятия & 4753 & 6846 & 6206 & 5210 & 5551 & 3760 & 4648 \\
\hline
\end{tabular}

Таблица 2. Динамика численности средних предприятий в Чеченской Республике и в целом по России (на конец года)

\begin{tabular}{|l|c|c|c|c|c|c|c|}
\hline & 2010 & 2011 & 2012 & 2013 & 2014 & 2015 & 2016 \\
\hline Российская Федерация & 25170 & 15945 & 13767 & 13684 & 13691 & 19278 & 13346 \\
\hline Чеченская Республика & 17 & 7 & 8 & 11 & 10 & 39 & 30 \\
\hline
\end{tabular}

Таблица 3. Динамика численности малых предприятий в Чеченской Республике и в целом по России (на конец года)

\begin{tabular}{|l|c|c|c|c|c|c|c|}
\hline & 2010 & 2011 & 2012 & 2013 & 2014 & 2015 & 2016 \\
\hline Российская Федерация & 229083 & 242677 & 243065 & 234537 & 235579 & 232369 & 172916 \\
\hline Чеченская Республика & 218 & 65 & 62 & 35 & 102 & 385 & 149 \\
\hline
\end{tabular}


Таблиц̧а 4. Динамика численности микропредприятий в Чеченской Республике и в целом по России (на конец года)

\begin{tabular}{|l|c|c|c|c|c|c|c|}
\hline & 2010 & 2011 & 2012 & 2013 & 2014 & 2015 & 2016 \\
\hline Российская Федерация & 1415186 & 1593755 & 1759973 & 1828589 & 1868201 & 1990003 & 2597646 \\
\hline Чеченская Республика & 4753 & 6846 & 6206 & 5210 & 5551 & 3760 & 4648 \\
\hline
\end{tabular}

рост их количества около 8\% ежегодно. Среднероссийские тенденции более устойчивые, колебания численности малых предприятий происходили в небольшом диапазоне - около от 1 до 6\% ежегодно относительно уровня 2010 года до 2015 года. Изменения численности малых предприятий в Чеченской Республике и в среднем по России в 2015 и 2016 годах совпадают. В целом, в 2016 году относительно 2010 года количество малых предприятий сократилось как в Чеченской Республике, так и в среднем по России - их количество составило 68\% и $75 \%$ соответственно от базового уровня.

Развитие динамики численности микропредприятий в Чеченской Республике кардинально отличается от тенденций численности средних и малых предприятий (см. табл. 4). Если общие модельные тенденции количества средних и малых предприятий, несмотря на неустойчивость, были положительными, то количество микропредприятий демонстрирует тенденцию к снижению - параметры линейного тренда $\mathrm{y}=-5.3665 \mathrm{x}+132.6$ говорят о среднем ежегодном снижении на 5\% относительно их количества в 2010 году. В то же время скачкообразное изменение приблизило количество микропредприятий в Чеченской Республике в 2016 году к уровню 2010 года. Общероссийские тенденции, напротив, говорят об устойчивом увеличении численности микропредприятий - линейный тренд $\mathrm{y}=15.356 \mathrm{x}+75.328$ показывает средний прирост около 15\% ежегодно относительно уровня 2010 года.

Структура предприятий по количеству работников в Чеченской Республике незначительно отличается от их структуры в среднем по России. Наибольшую долю предприятий в Чеченской Республике и в среднем по России составляют микропредприятия - 96\% и 93\% соответственно. Средние предприятия в исследуемой структуре составляют только 1\% как в Чеченской Республике, так и в России. Заметно отличается доля малых предприятий в Чеченской Республике - их доля в 2 раза меньше среднероссийского показателя, составляющего 6\% от общего количества МСП.
Анализ демографических тенденций организаций выявляет некоторые особенности развития малого и среднего предпринимательства в Чеченской Республике:

1. В целом прилагаются заметные усилия по улучшению бизнес-климата в Чеченской Республике - в отдельные годы можно наблюдать заметное увеличение численности предприятий, как микропредприятий, так и малых и средних предприятий. Особенно это заметно по увеличению численности малых и средних предприятий в 2015 году;

2. Меры развития малого и среднего предпринимательства в Чеченской Республике пока не смогли достичь устойчивости в его развитии, не обрели системный характер. Это предположение можно обосновать сильными скачками в демографии организаций;

3. Совпадение демографических тенденций организаций Чеченской Республики со среднероссийскими тенденциями в некоторые годы позволяет говорить, очевидно, о заметном воздействии глобальных факторов, связанных, вероятно, с нормативно-правовым, налоговым регулированием, а также с общеэкономическими тенденциями;

4. Отсутствие заметных положительных изменений в демографии микрорганизаций говорит о недостаточном внимании к их развитию, что сохраняет общую тенденцию снижения их количества. Проблемы развития микропредприятий должны стать приоритетом при реализации политики развития малого и среднего предпринимательства в регионе, так как их доля в общем количестве предприятий очень высокая;

5. Динамика «естественного движения» организаций в Чеченской Республике показывает общую тенденцию повышения «смертности» и снижения «рождаемости» организаций, а в последние годы количество официально ликвидированных организаций стало превышать количество вновь созданных организаций;

6. В силу объективных причин развитие микропредприятий должно стать драйвером общего роста деловой активности в Чеченской 
Республике. Во-первых, именно микропредприятия составляют основную долю предприятий МПС. Во-вторых, открытие малого микропредприятия является (или должно быть) более доступным направлением развития бизнеса с точки зрения юридического оформления, объема привлекаемых финансовых, трудовых ресурсов, аренды помещений и т.д.;

7. В то же время, относительно большое количество микропредприятий не позволяет принимать меры индивидуальной поддержки их развития - здесь необходима реализация системного подхода к повышению легкости открытия и ведения бизнеса;

8. Возрастная структура умерших предприятий в Чеченской Республике говорит о заметных проблемах как в бизнес-планировании, в предпринимательской грамотности населения, так и в системной государственной поддержке развития - количество ликвидированных однолетних предприятий в Чеченской Республике в два раза выше «младенческой смертности» в среднем по России (5,5\% ликвидированных од- нолетних предприятий против $2,4 \%$ в среднем по России). Больше всего в относительном выражении в Чеченской республике ликвидируются двухлетние предприятия - их доля среди всех ликвидированных предприятий в 2017 году близка к $14 \%$, а в среднем по России этот показатель равен 8,4\%;

9. Анализ динамики рождаемости и ликвидации организаций в Чеченской Республике говорит о том, что здесь демография населения, кардинально отличающаяся от среднероссийских тенденций в лучшую сторону, не стала существенным фактором воздействия на демографию организаций;

10. Структура населения Чеченской Республики и демографические тенденции в целом, говорят о большом потенциале республики, способном при эффективной социальноэкономической политике решить проблемы развития малого и среднего предпринимательства не только в Чеченской Республике, но и улучшить экономический климат в целом по России.

\section{Библиографический список}

1. Федеральная служба государственной статистики / Режим доступа // www.gks.ru

2. Официальный сайт общероссийской общественной организации малого и среднего предпринимательства «Опора России».- Режим доступа: http://opora.ru

3. Ильясов Р.Х. Демография организаций в Чеченской Республике: анализ тенденций // Вестник Чеченского государственного университета. 2018. -№ 3 (31). - С. 36-41.

4. Широков, Б.М. Малый бизнес. Финансовая среда предпринимательства / Б.М. Широков.- М.: Финансы и статистика, 2017.- 496 с.

5. Государственная программа РФ «Экономическое развитие и инновационная экономика» (утв. постановлением Правительства РФ от 15.04.2014 № 316);

6. Данные Комитет Правительства Чеченской Республики по малому бизнесу и предпринимательству за 2014-2018 годы.

7. Малое и среднее предпринимательство в России. Федеральная служба государственной статистики. URL: http://www.gks.ru

8. Малое предпринимательство в России. 2008-2017.

9. Предпринимательское право. Портал правовой поддержки предпринимательской деятельности. URL: http://businesspravo.ru

10. Регионы России. Социально-экономические показатели. 2008-2017. 